\title{
Evaluation of the Effects of the Belt and Road Initiative on the Unified Economic and Environmental Efficiency of Transportation Infrastructure in China Based on Range-Adjusted Measure Model and Difference in Difference Model
}

\author{
Yijiao Wang (iD) \\ School of Business, Xi'an University of Finance and Economics, Xi'an 710100, China \\ Correspondence should be addressed to Yijiao Wang; wangyijiao@xaufe.edu.cn
}

Received 22 September 2021; Revised 22 November 2021; Accepted 2 December 2021; Published 21 December 2021

Academic Editor: Fengtai Zhang

Copyright (c) 2021 Yijiao Wang. This is an open access article distributed under the Creative Commons Attribution License, which permits unrestricted use, distribution, and reproduction in any medium, provided the original work is properly cited.

\begin{abstract}
The Belt and Road Initiative has brought new opportunities for countries along the routes to develop their transportation infrastructure. Through large-scale transportation infrastructure construction, these countries enhanced the Belt and Road cooperation with each other, which further facilitates the rapid development of their own economy, but whether this can promote the sustainable development of their own environment, relevant research is still lacking. In this paper, China is taken as the study subject to evaluate the comprehensive effects that the Belt and Road Initiative exerts on the economy and environment through improving transportation infrastructure. In the study, RAM indicators were first established to measure the unified economic and environmental efficiency of transportation infrastructure, a DID model was then built to study the effects of the Initiative on the unified efficiency, and mediation models were finally created to discuss the ways in which the Belt and Road Initiative can improve the unified economic and environmental efficiency of transportation infrastructure through transformation and upgrade of industrial structure. The study result shows that the Belt and Road Initiative can significantly promote the improvement of the unified economic and environmental efficiency of the national transportation infrastructure, but the result is regionally heterogeneous. The Initiative has positive effects in improving the unified efficiency in eastern region but has no effect in the central and western regions. Although the Initiative can significantly enhance the efficiency through transforming and upgrading the industrial structure, the industrial structure rationalization plays a primary positive role. This paper provides the empirical evidences to evaluate the implementation effects of the Initiative in the transportation infrastructure sector and verifies that countries along the routes can achieve sustainable development through large-scale transportation infrastructure construction under the Belt and Road Initiative.
\end{abstract}

\section{Introduction}

The Belt and Road Initiative proposed by China is aimed at achieving common development and prosperity by enhancing interconnectivity and intercommunication. However, most of the countries along the routes are developing countries, where underdeveloped transportation infrastructure is a major bottleneck for economic development. Therefore, after the Belt and Road Initiative was put forward, transportation infrastructure has been prioritized for enhancing interconnectivity among countries and regions along the routes. Multilateral financial institutions including the Asian Infrastructure Investment Bank (AIIB) and the Silk Road Fund have been established through efforts under the Belt and Road Initiative to mitigate fund shortage for construction of large-scale transportation infrastructure. By December 2019, AIIB had provided USD 12.04 billion for 63 projects in countries and regions along the routes and the Silk Road Fund had signed 34 projects with a committed investment amount of USD 12.3 billion $[1,2]$. Since the Belt and Road Initiative was proposed, progress has been observed in the construction of transportation infrastructure. 
However, the financing environment for infrastructure investment has been changing constantly; especially, in recent years, the global economic landscape, trade environment, and industrial structure have been undergoing profound adjustments, which greatly impacts the global infrastructure industry. In the critical period of the Belt and Road Initiative with urgent demands on investment in transportation infrastructure, great attention needs to be paid on whether the Belt and Road Initiative has significantly improved the efficiency of transportation infrastructure investments in countries along the routes. Under the concept of sustainable development, the efficiency of transportation infrastructure investments in this paper refers to the unified economic and environmental efficiency of transportation infrastructure, that is, the ratio of investment input to the comprehensive economic and environmental outcomes.

\section{Literature Review}

The efficiency of transportation infrastructure investments needs to be specifically analyzed from the relationships between transportation infrastructure input and economic and environmental outcomes. Studies of transportation infrastructure concerning economy growth mainly focus on the following aspects: The first aspect is the logics between transportation infrastructure investment and economic growth. Rosenstein-Rodan and Rostow were the earliest to propose such opinion. Rodan's Big-Push theory pointed out that infrastructure construction, including transportation infrastructure, is the prerequisite for economic development. Rostow's Stages of Growth postulated that infrastructure, including transportation infrastructure, is of vital importance to economic growth, especially for developing countries, which should prioritize infrastructure construction [3,4]. With the evolution of econometrics, researchers began to use the empirical method in their studies and came to a universal opinion that investment in transportation infrastructure shows obvious driving on economy [5]. However, some researchers disagreed and held that there is no obvious positive correlation but a negative one between transportation infrastructure investments and economic growth. Some studies have found an inverted U-shaped relationship between transportation infrastructure and economic growth and most developing countries are still in the upward part of the curve due to insufficient infrastructure investments [6], while others have found that the contribution of infrastructure investments to economic growth in China is beginning to show a downward trend, showing an inverted L-shaped curve [7]. The second aspect is the channels and mechanisms whereby investment in transportation infrastructure affects economic growth. Numerous studies have shown that investment in transportation infrastructure can not only directly facilitate economic growth through the multiplier effect, but also indirectly boost the economy by reducing transportation and inventory costs [8], strengthening market integration [9], promoting importing and exporting activities [10, 11], changing household consumption patterns [12], influencing enterprise inventories, and accelerating the dynamic evolution of enterprises [13]. The third aspect is the heterogeneity of the effects of transportation infrastructure on economic growth. The effects of transportation infrastructure investment on economic growth vary from region to region [14]. Different types of transportation infrastructure also have varying effects on economic growth [15]. In addition, the effects of transportation infrastructure vary across different economic structures [16]. Existing studies of transportation infrastructure investment concerning environment mainly focus on the on the dynamics between transportation infrastructure and air quality. The reason might be that transportation infrastructure is closely related to the transportation industry. The current studies concluded that transportation infrastructure has both positive and negative effects on air quality. The main reason why transportation infrastructure can cause air pollution is that the growth rate of vehicles on roads is higher than that of road capacity for a long time, which is very likely to lead to traffic congestion and reduce vehicle speed, resulting in the amount of exhaust pollutant emissions 2-3 times higher than usual [17]. Increased road density due to road construction will increase energy consumption, which makes air pollution more serious [18]. On the other hand, transportation infrastructure is conducive to curb air pollution. Studies have found that increasing the road capacity or widening the roads can effectively reduce traffic congestion to a certain extent and improve fuel efficiency to reduce exhaust emissions [19]. Railway transportation can effectively alleviate traffic congestion in large cities by substituting taxies and other transportation equipment, which further saves energy and reduces exhaust emissions [20]. High-speed railway is also conducive to energy saving and emission reduction due to the low consumption of fossil fuels during passenger and cargo transportation [21]. Under the concept of sustainable development, any unilateral consideration of the effect of transportation infrastructure investment on the economy or environment is one-sided. Although there are existing studies involving the evaluation on the coordinated benefits of the economy, environment, and society brought by transportation infrastructure [22], researches about the comprehensive effects of transportation infrastructure investment on the economy and environment are still in the preliminary stage.

According to the existing evaluation methods used in the research on the impact of transportation infrastructure investment, the more used methods are divided into the following different categories. (1) Input-output analysis method: in the relevant research on the growth effects of transportation infrastructure, the production function method is currently the most used research method, and the Cobb-Douglas production function is the most widely used. The production function method was mainly used for the following research purposes: First, transport infrastructure capital was separated from the total capital as an independent form of capital, and then production function was used to estimate the output elasticity and optimal scale of transport infrastructure. Aschauer and Munnel adopted the production function model to analyze whether infrastructure can promote economic growth $[5,23]$. The second was 
to strengthen the correlation between transport infrastructure investment and economic growth or productivity improvement and explored the spatial spillover effect generated by transport infrastructure based on the production function. In addition to paying attention to the impact of transportation infrastructure on the economic growth of the region, Liu and Cantos et al. also noted that the transportation infrastructure is likely to promote the transfer of economic activities in the region to its surrounding areas, resulting in a certain economic spillover effect $[24,25]$. (2) Analytical method of index system construction: here is a general introduction to the Data Envelopment Analysis (DEA) method. The DEA method is a nonparametric method that relies on mathematical tools to evaluate the effectiveness of the economic system at its production frontier. It is mainly applicable to the performance evaluation of multiobjective decision making units with multiinputs and multioutputs. Although DEA is based on the input-output perspective, it is different from the individual input and output elements of the production function. The input and output ends of DEA need to construct a certain index system to consider the complex situation of the research. Therefore, the use of DEA to evaluate the impact of transportation infrastructure is systematic and comprehensive. Among the DEA models, the CCR model and the BCC model were proposed by Charnes et al. and Banker, respectively, and they are the most widely used [26, 27]. Li and Li used the two-stage DEA method to effectively evaluate the performance of China's infrastructure investment [28]. Sun et al. used the cross-efficiency DEA model to evaluate the economic benefits generated by the public infrastructure of Chinese cities [29]. In addition, the game cross-efficiency DEA model and the parallel DEA model were also used in related problems [30, 31]. (3) Systematic comprehensive analysis method: system dynamics was first proposed by Forrester in his "Industrial Dynamics" edited in the 1950s [32]. It is a quantitative analysis tool based on system theory, information theory, and cybernetics, while using computer simulation technology to study complex social systems. This method can solve the nonlinear, multiloop, high-level, and dynamic problems that were difficult to achieve in the previous econometric models. Artificial neural network was first proposed by $\mathrm{McCulloch}$ and Pitts. It is a complex network structure formed by a large number of processing units (neurons) interactively connected. Its principle is mainly to simplify, abstract, and simulate the neural structure of the human brain and its operating activities [33]. Because the problems involved in the transportation field are highly nonlinear and the characteristics of related data are usually large, complex and dynamic, the application of these two methods in related research in the transportation field has certain advantages. (4) Other evaluation methods: there are other evaluation methods used in the research on the impact of transportation infrastructure investment. Based on the analysis of the gravity model, Liu et al. established a gravity model to investigate the influence of transportation infrastructure on the boundary effect [34]. Based on the analysis of the stochastic frontier model, Gong and Yin used the heterogeneous stochastic frontier model to empirically analyze the impact of railway construction on the inefficiency of regional trade [35].

In recent years, studies concerning the Belt and Road Initiative and transportation infrastructure have been increasing extensively. These studies specifically focus on the dynamics between construction of transportation infrastructure and economic and social development in countries along the routes. A general conclusion has been reached through empirical analysis that construction of transportation infrastructure can reduce unemployment and effectively increase the economic aggregate and output per capita in countries along the routes. Main factors impacting investment in transportation infrastructure in countries along the routes have been analyzed, which include multilateral financial institutions, investment entities, and financial factors such as financing costs, financing efficiency, and financing risks [36]. The mechanisms whereby construction of transportation infrastructure affects economic growth in countries along the routes have been studied, among which foreign trade and trade structure improvement all play a positive role [37]. And studies have been done to assess the investment efficiency in relation to transportation infrastructure in countries along the routes and a conclusion has been reached that investment in different types of transportation infrastructure has a varying effect on economic growth in countries along the routes. Statistics show that the Belt and Road Initiative is mainly used as the basis for zoning in existing studies, while its effects on policies concerning investment in transportation infrastructure have rarely been studied.

In summary, first of all, in recent years, studies on the impacts of transportation infrastructure investment on economic growth and environmental development have gradually been increasing, but no study has been dedicated to the impacts on the comprehensive economic and environmental development. Based on this, when investigating the level of transportation infrastructure investment, this paper analyzed the impacts of transportation infrastructure investment on the comprehensive development of economy and environment, which is in line with the requirements of the current global sustainable development concept. The impact evaluation method adopted was selected according to the composition principle and scope of application of various evaluation methods and combined with the research objectives of this paper. Considering that the evaluation of the investment level of transportation infrastructure in this paper was based on the input-output perspective, a series of indicators needed to be set at the input and output ends, so the DEA method was more appropriate. Second, lots of studies explained the importance of the Belt and Road Initiative on the transportation infrastructure construction at the theoretical level but lacked empirical verification. Therefore, a DID model was built in this paper to empirically verify the effects of the Belt and Road Initiative on the unified economic and environmental efficiency of transportation infrastructure in China. Finally, China is at the critical stage for industrial structure adjustment. The transformation and upgrade of the industrial structure have 
been put onto the national agenda for strategic development. Therefore, this paper discussed whether the transformation and upgrade of the industrial structure play a mediating role in better facilitating the Belt and Road Initiative to enable the improvement of the unified economic and environmental efficiency of transportation infrastructure.

\section{Research Assumptions}

The effects of the Belt and Road Initiative on the unified economic and environmental efficiency of transportation infrastructure can be analyzed from the demand driving, investment increasing, and effectiveness. At present, countries along the routes have reached a broad consensus on advancing the Belt and Road cooperation; the key is connectivity. Infrastructure is the bedrock of connectivity while the lack of infrastructure is a bottleneck that held up the development of many countries. Therefore, the demand for developing infrastructure, especially transportation infrastructure, has been relatively huge since the proposal of the Belt and Road Initiative. According to BMI's statistics on global infrastructure projects, in 2018, transportation infrastructure accounted for the highest proportion of energy, transportation, telecommunications, and water infrastructure by the value of new contracts signed by belt-and-road countries [38]. Most countries along the routes are developing countries. In the coming years, the accelerated industrialization and urbanization will generate new demands for transportation infrastructure development. In the Belt and Road Infrastructure Development Index Report 2019, the transportation infrastructure industry in each belt-androad country remains an investment hotspot [39], and development and policy-oriented financial institutions, commercial banks, and special investment funds constitute the main financing channels to alleviate the shortage of funds for infrastructure construction in countries along the routes. It can be seen that the Belt and Road Initiative has strongly boosted the demands for transportation infrastructure construction and kept absorbing the huge influx of investment in transportation infrastructure for a long time. However, transportation infrastructure investment with such a huge scale is bound to have profound effects on the economic and environmental development in countries along the Belt and Road. Under the Belt and Road Initiative, as the transportation infrastructure has gradually been improved to increase connectivity, the layout of industrial investments has been further optimized, and economic and trade cooperation has been upgrading, leading to accelerated economic development of the countries along the routes [40]. In addition, large-scale road construction alleviates traffic congestion, leading to energy saving and emission reduction. The technology spillover effect of transportation infrastructure has resulted in the extensive application of advanced environmental protection technologies, which all have played a positive role in the environmental development of countries along the routes [41]. In conclusion, the following assumption was proposed in this paper.
Assumption 1. The Belt and Road Initiative has a positive effect in improving the unified economic and environmental efficiency of transportation infrastructure.

The effects that the Belt and Road Initiative exerts on the unified economic and environmental efficiency through transforming and upgrading the industrial structure can be analyzed from the relationships between the paths for the Belt and Road Initiative to affect transformation and upgrade of the industrial structure and the transportation infrastructure investment. The Belt and Road Initiative can effectively solve problems such as insufficient market demands and overcapacity, and effective market demands are necessary conditions for transforming and upgrading the industrial structure [42]. The countries along the Belt and Road have relatively large differences in resource endowments, resulting in a strong economic complementarity. Increasing trade exchanges between these countries facilitate the flow of resource elements, and the reorganization and optimization of resource elements will have an important impact on the rational adjustment of the industrial structure [43]. The Belt and Road Initiative not only helps Chinese enterprises to increase investment in research and technological development to gain market competitive advantages, but also helps Chinese enterprises to introduce advanced technologies, equipment, and management experience from foreign countries to enhance their own strength. Relying on internal innovation or pushing technological innovation using advanced foreign technologies can drive the upgrade of the industrial structure [44]. This shows that the implementation of the Belt and Road Initiative facilitates the transformation and upgrade of the industrial structure. In the above paths that affect the transformation and upgrade of the industrial structure, market demands, the flow of resource elements, and technological innovation and spillover must be achieved through the joint construction of transportation infrastructure to facilitate free trade and reduce transaction costs. Therefore, the Belt and Road Initiative can increase investment in transportation infrastructure through transforming and upgrading the industrial structure while the sound transportation infrastructure will further boost the comprehensive development of the economy and the environment. In conclusion, the following assumption was proposed in this paper.

Assumption 2. The Belt and Road Initiative can improve the unified economic and environmental efficiency of transportation infrastructure through transforming and upgrading the industrial structure.

In summary, the research framework of this article is shown in Figure 1.

\section{Methods}

4.1. Range-Adjusted Measure (RAM) Model. Before conducting the study, the unified economic and environmental efficiency of transportation infrastructure needs to be measured. Because the RAM model can not only eliminate 


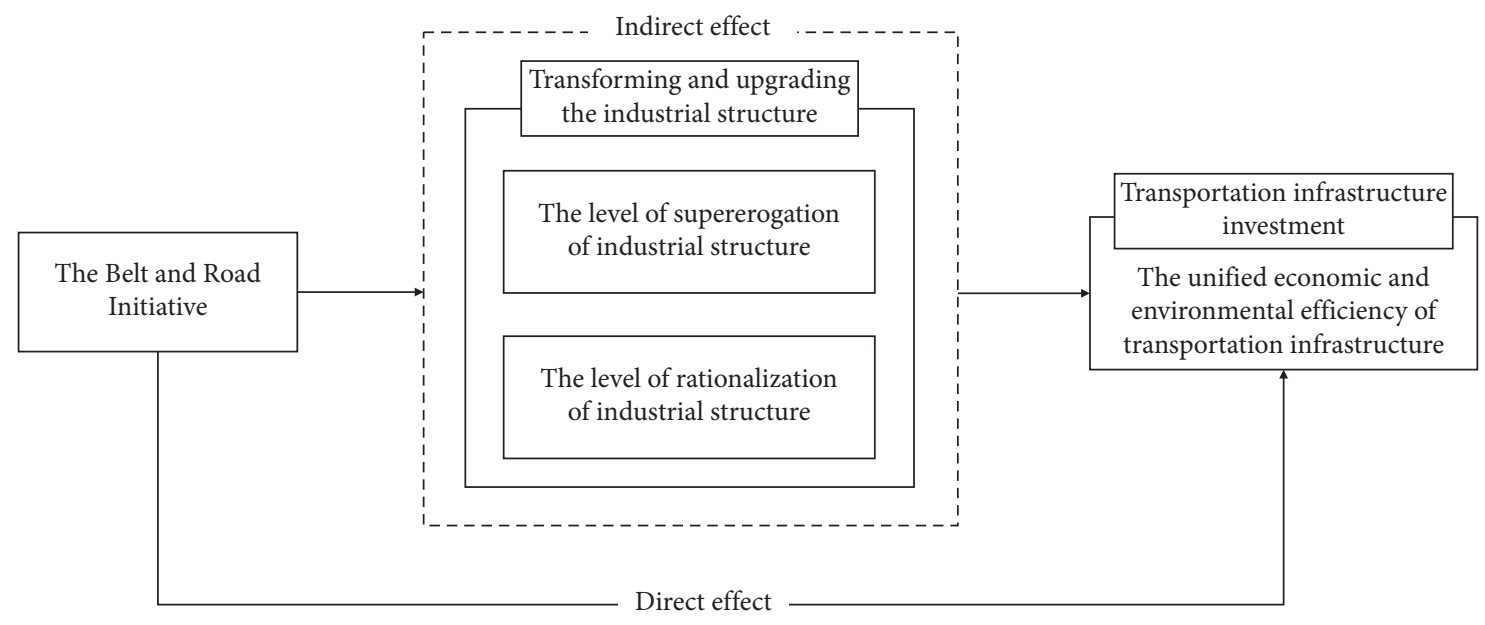

Figure 1: The research framework of this article.

the angle, radial, and nonrelaxation variable problems of the traditional data envelopment analysis model, but also has an additive structure to achieve independent efficiency measurements based on expected output and undesired output, respectively, and integrate and add the independent efficiency of the two [45]. Therefore, this paper adopted the RAM model to measure the unified economic and environmental efficiency of transportation infrastructure, which measured the investment level of transportation infrastructure in China. The investment level of transportation infrastructure measured from the perspective of sustainable development is more reasonable than traditional measurement standards, and it can be able to make a more comprehensive and accurate evaluation of the true investment level of transportation infrastructure in China at this stage.

\subsubsection{RAM Model for Economic, Environmental, and Unified Efficiency}

(1) RAM Model for Economic Efficiency. The economic efficiency RAM model based on the desirable output is expressed as

$$
\max \left\{\left.\left(\sum_{n=1}^{N} R_{n}^{x} s_{n}^{x}+\sum_{p=1}^{p} R_{p}^{y} s_{p}^{y}\right)\right|_{j=1} ^{\sum_{j=1}^{J} x_{n j} \lambda_{j}+s_{n}^{x}=x_{n j}, \forall n ; \sum_{j=1}^{J} y_{p j} \lambda_{j}-s_{p}^{y}=y_{p j}, \forall p ;} \begin{array}{c}
\sum_{j=1}^{J} \lambda_{j}=1, \lambda_{j} \geq 0, \forall j ; s_{n}^{x} \geq 0, \forall n ; s_{p}^{y} \geq 0, \forall p ;
\end{array}\right\} .
$$

In the above model, $x_{n j}$ and $y_{p j}$ are, respectively, the $n$th ordinary input factor and the $p$ th desirable output factor in region $j ; \lambda_{j}$ is the weight of region $j ; R_{n}^{x}$ and $R_{p}^{y}$ are, respectively, the adjustment range of slack $s_{n}^{x}$ and $s_{p}^{y}$, expressed as

$$
\left.\begin{array}{l}
R_{n}^{x}=\frac{1}{(N+P)\left[\operatorname{Max}\left(x_{n j}\right)-\operatorname{Min}\left(x_{n j}\right)\right]} \\
R_{p}^{y}=\frac{1}{(N+P)\left[\operatorname{Max}\left(y_{p j}\right)-\operatorname{Min}\left(y_{j}\right)\right]}
\end{array}\right\} .
$$

Assume that $\lambda^{*}$ is the weight of the observed cross section of the maximum relative efficiency during the economic production in each region when model (1) achieves the optimal solution status; and $s_{n}^{x^{*}}$ and $s_{p}^{y^{*}}$ are, respectively, the input slack and the output slack in the optimal solution status. Then, the RAM economic efficiency index of the $t$ th year of region $j$ may be converted to

$$
0 \leq \theta_{p}=1-\left(\sum_{n=1}^{N} R_{n}^{x} s_{n}^{x^{*}}+\sum_{p=1}^{p} R_{p}^{y} s_{p}^{y^{*}}\right) \leq 1 .
$$

(2) RAM Model for Environmental Efficiency. The environmental efficiency RAM model based on undesirable output is expressed as 


$$
\max \left\{\begin{array}{c}
\left(\sum_{n=1}^{N} R_{n}^{x} s_{n}^{x}+\sum_{m=1}^{M} R_{m}^{e}\left(s_{m}^{e^{+}}+s_{m}^{e^{-}}\right)+\sum_{i=1}^{I} R_{i}^{b} s_{i}^{b}\right) \mid \sum_{j=1}^{J} x_{n j} \lambda_{j}+s_{n}^{x}=x_{n j}, \quad \forall n ; \\
\sum_{j=1}^{J} e_{m j} \lambda_{j}-s_{m}^{e^{+}}+s_{m}^{e^{-}}=e_{m j}, \quad \forall m ; \sum_{j=1}^{J} b_{i j} \lambda_{j}+s_{i}^{b}=b_{i j}, \forall i ; \\
\sum_{j=1}^{J} \lambda_{j}=1, \lambda_{j} \geq 0, \forall j ; s_{n}^{x} \geq 0, \quad \forall n ; s_{m}^{e^{+}} \geq 0, s_{m}^{e^{-}} \geq 0, \forall m ; s_{i}^{b} \geq 0, \forall i
\end{array}\right\} .
$$

In the above model, $e_{m j}$ and $b_{i j}$ are, respectively, the mth energy input factor and the $i$ th undesirable output factor in region $j ; s_{m}^{e^{+}}$and $s_{m}^{e^{-}}$are the two slacks of the $m$ th energy input, where the symbols + and - indicate, respectively, the two projection direction of energy increase and energy decrease; $R_{m}^{e}$ and $R_{i}^{b}$ are, respectively, the adjustment range of the slacks $s_{m}^{e^{+}}, s_{m}^{e^{-}}$, and $s_{i}^{b}$, expressed as

$$
\left.\begin{array}{l}
R_{m}^{e}=\frac{1}{(N+M+I)\left[\operatorname{Max}\left(e_{m j}\right)-\operatorname{Min}\left(e_{m j}\right)\right]} \\
R_{i}^{b}=\frac{1}{(N+M+I)\left[\operatorname{Max}\left(b_{i j}\right)-\operatorname{Min}\left(b_{i j}\right)\right]}
\end{array}\right\} .
$$

In this paper, $\mathrm{CO}_{2}$ emission is the only undesirable output, because greenhouse gases emission mainly based on
$\mathrm{CO}_{2}$ is important indicator affecting the environmental sustainable development of transportation infrastructure. $s_{m}^{e++^{*}}, s_{m}^{e^{-*}}$, and $s_{i}^{b^{*}}$ are, respectively, the slacks of input and output in the optimal solution status. According to model (4), the RAM environmental efficiency index of the $t$ th year of region $j$ may be converted to

$$
0 \leq \theta_{E}=1-\left(\sum_{n=1}^{N} R_{n}^{x} s_{n}^{x^{*}}+\sum_{m=1}^{M} R_{m}^{e}\left(s_{m}^{e+*}+s_{m}^{e-*}\right)+\sum_{i=1}^{I} R_{i}^{b} s_{i}^{b^{*}}\right) \leq 1 .
$$

(3) RAM Model for Unified Efficiency. The additive structure of the RAM model is used to integrate the economic efficiency and the environmental efficiency in a single framework to obtain the RAM model for the unified efficiency:

$$
\max \left\{\begin{array}{c}
\left(\sum_{n=1}^{N} R_{n}^{x} s_{n}^{x}+\sum_{m=1}^{M} R_{m}^{e}\left(s_{m}^{e^{+}}+s_{m}^{e^{-}}\right)+\sum_{p=1}^{p} R_{p}^{y} s_{p}^{y}+\sum_{i=1}^{I} R_{i}^{b} s_{i}^{b}\right) \mid \sum_{j=1}^{J} x_{n j} \lambda_{j}+s_{n}^{x}=x_{n j}, \quad \forall n ; \\
\sum_{j=1}^{J} e_{m j} \lambda_{j}-s_{m}^{e^{+}}+s_{m}^{e^{-}}=e_{m j}, \quad \forall m ; \sum_{j=1}^{J} y_{p j} \lambda_{j}-s_{p}^{y}=y_{p j}, \forall p ; \\
\sum_{j=1}^{J} b_{i j} \lambda_{j}+s_{i}^{b}=b_{i j}, \quad \forall i ; \sum_{j=1}^{J} \lambda_{j}=1, \lambda_{j} \geq 0, \forall j ; s_{n}^{x} \geq 0, \forall n ; s_{m}^{e^{+}} \geq 0, \\
s_{m}^{e^{-}} \geq 0, \quad \forall m ; s_{p}^{y} \geq 0, \forall p ; s_{i}^{b} \geq 0, \forall i
\end{array}\right\} .
$$

When model (7) achieves the optimal solution status, the RAM unified efficiency index of the $t$ th year of region $j$ may be converted to

$$
\begin{aligned}
0 \leq \theta_{U}= & 1-\left(\sum_{n=1}^{N} R_{n}^{x} s_{n}^{x^{*}}+\sum_{m=1}^{M} R_{m}^{e}\left(s_{m}^{e++^{*}}+s_{m}^{e-*^{*}}\right)\right. \\
& \left.+\sum_{p=1}^{p} R_{p}^{y} s_{p}^{y^{*}}+\sum_{i=1}^{I} R_{i}^{b} s_{i}^{b^{*}}\right) \leq 1
\end{aligned}
$$

\subsubsection{Indicators and Data}

(1) Indicator selection and data sources: in consideration of the characteristics of transportation infrastructure in combination with research findings in existing literature $[46,47]$, the indicators and data sources were selected to measure the unified efficiency of economy and environment of transportation infrastructure, as shown in Table 1. Due to lack of data in Tibet, Hong Kong, Macau, and Taiwan, the panel data of 30 provinces and cities other than the above from 2007 to 2018 were collected in the study.

(2) Indicator processing:

Capital stock: in this paper, the perpetual inventory method was used to estimate the capital stock of the transportation industry. The formula used in the calculation is $K_{i t}=I_{i t}+(1-\delta) K_{i t-1}$, where $K_{i t}$ is the capital stock of the transportation industry in the $t$ th year of region $i ; I_{i t}$ is the investment in transportation in the $t$ th year of region, expressed 
TABLE 1: Indicators used to assess unified economic and environmental efficiency of transportation infrastructure.

\begin{tabular}{|c|c|c|c|c|}
\hline Category & Indicator & Quantized value & Unit & Data source \\
\hline \multirow{3}{*}{$\begin{array}{l}\text { Input } \\
\text { indicators }\end{array}$} & Capital stock & $\begin{array}{c}\text { Capital stock of the transportation } \\
\text { industry }\end{array}$ & $\begin{array}{l}\text { RMB } 100 \\
\text { million }\end{array}$ & China Statistical Yearbook \\
\hline & Labor & $\begin{array}{l}\text { Number of persons employed in the } \\
\text { transportation industry }\end{array}$ & Persons & China Statistical Yearbook \\
\hline & $\begin{array}{c}\text { Energy } \\
\text { consumption }\end{array}$ & $\begin{array}{c}\text { Energy consumption in the } \\
\text { transportation industry }\end{array}$ & $\begin{array}{c}10,000 \mathrm{t} \\
\text { standard coal }\end{array}$ & China Energy Statistical Yearbook \\
\hline \multirow{3}{*}{$\begin{array}{l}\text { Output } \\
\text { indicators }\end{array}$} & \multirow{2}{*}{$\begin{array}{l}\text { Desirable } \\
\text { output }\end{array}$} & $\begin{array}{l}\text { Gross production of the } \\
\text { transportation industry }\end{array}$ & $\begin{array}{l}\text { RMB } 100 \\
\text { million }\end{array}$ & China Statistical Yearbook \\
\hline & & $\begin{array}{l}\text { Comprehensive converted turnover } \\
\text { of the transportation industry }\end{array}$ & $\begin{array}{l}100 \text { million ton } \\
\text { kilometer }\end{array}$ & China Statistical Yearbook \\
\hline & $\begin{array}{l}\text { Undesirable } \\
\text { output }\end{array}$ & $\begin{array}{c}\mathrm{CO}_{2} \text { mission of the transportation } \\
\text { industry }\end{array}$ & $10,000 \mathrm{t}$ & $\begin{array}{c}\text { China Energy Statistical Yearbook, } 2006 \text { IPCC } \\
\text { Guidelines for National Greenhouse Gas } \\
\text { Inventories }\end{array}$ \\
\hline
\end{tabular}

here as the investment in fixed assets in transportation; $\delta$ is the rate of depreciation, i.e., 9.6\%. To exclude the effects of the price factor, the capital stock data here were all converted to constant-price data taking 2007 as the base period.

Labor: this is the number of persons employed in the transportation industry in each region.

Energy consumption: the total consumptions of coal, gas, diesel, and natural gas in the transportation industry were converted to standard coal based on their respective conversion coefficient, to obtain the total energy consumption.

Desirable output: this includes the gross production and the comprehensive converted turnover of the transportation industry. To exclude effects of the price factor, the gross production was adjusted to a constant-price value taking 2007 as the base period based on the index of value added of the service sector. The comprehensive converted turnover was calculated based on the conversion coefficients between turnover of passenger transportation and that of freight transportation set out in the Chinese statistical system as shown in Table 2. In consideration of data availability, data of air transportation was not considerate and waterway transportation was calculated by a converted coefficient of $1 / 3$.

Undesirable output: this is $\mathrm{CO}_{2}$ emission of the transportation industry. The bottom-up method in the IPCC [48] guidelines was used to calculate the undesirable output based the various energy consumptions. The calculation formula is $T C_{i t}=\sum_{n=1}^{m} E_{n} F_{\text {nit }}$, where $T C_{i t}$ is the $\mathrm{CO}_{2}$ emission in the th year in region $i$; $E_{n}$ is the $\mathrm{CO}_{2}$ emission factor of the $n$th energy; $F_{\text {nit }}$ is the consumption of the $n$th energy in the $t$ th year in region $i$; $m$ is the type of energy consumed.

4.2. Difference in Difference (DID) Model. In order to study the effects of the Belt and Road Initiative on the unified economic and environmental efficiency of transportation infrastructure in China, the difference method may be used to obtain the efficiency difference before and after the
TABLE 2: Conversion coefficients used in comprehensive concerted turnover.

\begin{tabular}{lcccc}
\hline $\begin{array}{l}\text { Transportation } \\
\text { mode }\end{array}$ & Railway & Road & Waterway & Air \\
\hline $\begin{array}{l}\text { Conversion } \\
\text { coefficient }\end{array}$ & 1 & $1 / 10$ & $\begin{array}{c}1 / 3 \text { (for seats) and } 1 \\
\text { (for sleepers) }\end{array}$ & $1 / 13$ \\
\hline
\end{tabular}

proposal to determine the effect of the Initiative on the efficiency. However, there may be other policies or factors that affect efficiency before and after the Initiative was proposed, and the difference method cannot take these into account, which may lead to overestimation of the effect of the Initiative. Therefore, a more scientific method, i.e., Difference in Difference, was used here to evaluate the effects of the Belt and Road Initiative on the unified economic and environmental efficiency of transportation infrastructure.

4.2.1. Setup of DID Model. This paper takes the Belt and Road Initiative as a quasinatural experiment and draws on the existing researches to select regions along the Belt and Road as the treated group and those not along the routes as the control group [49]. The regions along the Belt and Road here are the 17 provinces and cities along the routes in China mentioned in the "Vision and Actions on Jointly Building Silk Road Economic Belt and 21st-Century Maritime Silk Road" [50], namely, the Inner Mongolia, Liaoning, Jilin, Heilongiiang, Shanghai, Zhejiang, Fujian, Guangdong, Guangxi, Hainan, Chongqing, Yunnan, Shaanxi, Gansu, Qinghai, Ningxia, and Xinjiang (of which the data is not included here due to the incompleteness of data of Tibet). The DID model thus established is shown as

$$
U E_{i t}=\beta_{0}+\beta_{1} \operatorname{silkroad}_{i} * \text { post }_{t}+\alpha X_{i t}+\gamma_{t}+\mu_{i}+\varepsilon_{i t} .
$$

In the above model, $U E_{i t}$ is the unified economic and environmental efficiency of transportation infrastructure in the th year in region $i$; silkroad ${ }_{i}$ is a grouping dummy variable used to determine whether region $i$ is located along the Belt and Road; post $_{t}$ is a phasing dummy variable used to determine whether the Belt and Road Initiative has been proposed by the $t$ th year; $\operatorname{silkroad}_{i} *$ post $_{t}$ is an initiative dummy variable, expressed as an interaction between the 
grouping dummy variable and the phasing dummy variable; $X_{i t}$ is a control variable; $\gamma_{t}$ is the time fixed effect; $\mu_{i}$ is the region fixed effect; and $\varepsilon_{i t}$ is the random error.

4.2.2. Variables and Data. Due to the lack of relevant data in Tibet, Hong Kong, Macao, and Taiwan, the panel data of 30 provinces and cities in China from 2007 to 2018 except for the above regions were collected in the study. The selected variables and data sources are as follows:

(1) Explained variable $U E_{i t}$ :

Based on the purpose of this paper, the unified economic and environmental efficiency of transportation infrastructure was selected as the explained variable. Its value was obtained by measurement using the RAM model.

(2) Core explanatory variable silkroad ${ }_{i} *$ post $_{t}$ :

An interaction between the grouping dummy variable and the phasing dummy variable was taken as the core explanatory variable. The variable silkroad ${ }_{i}$ is a dummy variable used to determine whether region $i$ is along the routes. It is set to 1 if region $i$ is along the routes, or otherwise it is set to 0 ; the variable post $t_{t}$ is a dummy variable used to determine whether the Belt and Road Initiative has been proposed by the th year. Since the Initiative was proposed in 2013, it is set to 1 for all the years after 2013 (included) and to 0 for all the years before 2013 .

(3) Control variable:

When considering the effects of the Belt and Road Initiative on the unified economic and environmental efficiency of transportation infrastructure, it is necessary to control the factors that affect the input and output levels of transportation infrastructure. Combined with previous studies $[46,51,52]$, the control variable $X_{i t}$ included the following: the scale of the transportation industry (tid), expressed as the value added of the industry and adjusted to a constant-price value taking 2007 as the base period based on the index of value added of the service sector to exclude the effect of the price factor; transportation structure ( $t s)$, expressed as the ratio of the converted turnover of road transportation to the comprehensive converted turnover of the transportation industry; urbanization level ( $u r b$ ), expressed as the ratio of nonagricultural population to the total population of a region; opening-up level (open), expressed as the ratio of the total volume of import and export to the GDP of the same year; population employed in the industry ( $p o p$ ), expressed as the number of persons employed in the transportation industry; and density of transportation network (tnd), expressed as the ratio of the sum of total railway length, road length, and inland waterway length to the total land area of the province or city concerned. Among these, data of tid, ts, and pop come from China Statistical Yearbook; data of urb come from China Population and Employment Statistics Yearbook; data of open come from the Statistical Yearbook of each region; and data of $t n d$ come from China Statistical Yearbook and China Statistical Yearbook for Regional Economy.

4.3. Mediation Models. In order to further investigate whether the implementation of the Belt and Road Initiative can improve the unified economic and environmental efficiency of transportation infrastructure through transforming and upgrading the industrial structure, this paper set up mediation models that take the status of the industrial structure transformation and upgrade as the mediating variable.

4.3.1. Setup of Mediation Models. Considering that this paper measured the transformation and upgrade of the industrial structure from two dimensions, the level of supererogation of industrial structure and the level of rationalization of industrial structure, parallel multiple mediation models were set up in this paper. The established models are shown as

$$
\begin{aligned}
\text { Upgrade }_{i t} & =\sigma_{0}+\sigma_{1} \text { silkroad }_{i} * \text { post }_{t}+\sigma_{2} X_{i t}+\gamma_{t}+\mu_{i}+\varepsilon_{i t}, \\
\text { Ration }_{i t} & =\partial_{0}+\partial_{1} \text { silkroad }_{i} * \text { post }_{t}+\partial_{2} X_{i t}+\gamma_{t}+\mu_{i}+\varepsilon_{i t}, \\
U E_{i t} & =\delta_{0}+\delta_{1} \text { silkroad }_{i} * \text { post }_{t}+\delta_{2} \text { Upgrade }_{i t}+\delta_{3} \text { Ration }_{i t}+\delta_{4} X_{i t}+\gamma_{t}+\mu_{i}+\varepsilon_{i t} .
\end{aligned}
$$

In the above models, two mediating variables Upgrade $_{i t}$ and Ration ${ }_{i t}$, are, respectively, the level of supererogation and the level of rationalization in the th year in region $i$. The meanings of other variables are the same as in model 9. The mediation effect of the level of supererogation is $\sigma_{1} \delta_{2}$ while the mediation effect of the level of rationalization is $\partial_{1} \delta_{3}$. Therefore, the total mediation effect can be obtained by adding the two effects, which is $\sigma_{1} \delta_{2}+\partial_{1} \delta_{3}$. In addition, the direct effect of the Belt and Road Initiative on the unified economic and environmental efficiency of transportation infrastructure is $\delta_{1}$.

Explanation of mediating variables: (1) the level of supererogation of industrial structure is a measurement of industrial structure upgrade. Specifically, it refers to the shift 
of industrial structure from low-end to middle and high-end level, which can be manifested in the transition from the primary sector to the secondary and tertiary sector, the evolution of labor and capital-intensive industries to knowledge- and technology-intensive industries, and the shift from low-value-added industries to high-value-added industries. This paper uses the ratio of the output value of the tertiary industry to the output value of the secondary industry to reflect the level of supererogation. (2) The level of industrial structure rationalization is a measurement of the coordination capacity and the level of correlation among the three major industries. Specifically, it refers to the process by which higher economic outputs are ultimately generated by rationally allocating production factors and coordinating industry development under the existing resources and technological conditions. In this paper, the industrial structure rationalization was measured with reference to existing methods using the Theil index [53]. The formula used in the calculation is Ration $i t=\sum_{m=1}^{3} Y_{\text {mit }} / Y_{i t} \ln$ $\left(\left(Y_{\text {mit }} / L_{\text {mit }}\right) /\left(Y_{i t} / L_{i t}\right)\right)$, where $Y_{\text {mit }}$ and $L_{\text {mit }}$ are, respectively, the output value and number of employees of industry $m$ in the $t$ th year of region $i$. The Theil index reflects the industrial structure and employment structure of three major industries. If the index is 0 , the industrial structure in the region is at a balanced level. Conversely, the industrial structure is unbalanced and irrational. Considering that the industrial structure rationalization level calculated by the Theil index is a reverse index, in order to facilitate analysis, this paper adopts the range transformation method to forward the industrial structure rationalization level. The specific samples and years of the two variables are selected as above, and the data required for the calculation comes from the China Statistical Yearbooks and statistical yearbooks of various provinces and cities.

4.3.2. Methods to Test Mediation. Two main approaches are commonly applied to assess and test mediation. The first approach is called the product of coefficients (that is to test $H_{0}: a b=0$ ), and the second is called the difference of coefficients approach (that is to test $H_{0}: c-c^{\prime}=0$ ). For specific definitions about $a, b, c$, and $c l$, see relevant literature [54], which will not be discussed in this paper. Since the type I error rate of the difference of coefficients approach is significantly higher than that of the product of coefficients, the difference of coefficients approach is rarely discussed now $[55,56]$. The product of coefficients approach can be divided into direct testing or indirect testing. Indirect testing is to indirectly test the significance of the product of the coefficients $a b$ by sequentially testing the significance of the regression coefficients $a$ and $b$. Direct testing is to directly test the significance of the coefficient product $a b$. Direct testing methods include Sobel test, Monte Carlo Method (MCMC), and Bootstrap method. The advantages and disadvantages of the above-mentioned methods are all discussed as follows: Sequential testing method has a low type I error rate but the testing power is relatively low [57]; the Sobel method has a higher testing power than sequential testing, but the main limitation lies in the fact that the significance can be determined only when the distribution of the product of the coefficients is normal at large sample sizes. Even if each coefficient obeys a normal distribution, the product of the coefficients is not usually normal [58-60]. Although the MCMC method has a higher testing power than the Sobel method, it requires more statistical knowledge and complex algorithms and also involves prior distribution, which is controversial [61, 62]; the Bootstrap method not only has a higher testing power than the Sobel method but also can better replace the Sobel method as it does not require a normal distribution of product of the coefficients [57,60]. In the consideration of the advantages and disadvantages of various methods of the product of coefficients approach, some scholars suggested carrying out the sequential testing first. If the test result is obvious, it can be proved that there is a mediation effect. This is because the testing power of the sequential testing method is the lowest among all methods. If the mediation effect is tested to be significant, the result is very convincing. However, if the test result is not obvious, the Bootstrap method with the highest testing power will be used instead [63]. The above test steps can be better applied to a simple mediation effect test with a single mediating variable. Since the multiple mediation models involve more variables and the paths are more complex, it is more ideal to directly use the Bootstrap method to test multiple mediation effects. In summary, this paper first estimated the models from (10) to (12), conducted a preliminary analysis of the mediation effects based on the estimated results, and then used the Bootstrap method to test the significance of individual mediation effects and the overall mediation effect.

\section{Results and Discussion}

\subsection{Unified Economic and Environmental Efficiency of Transportation Infrastructure}

5.1.1. Calculation Results of Efficiency. According to formulas (1)-(8), the software MAXDEA was used to measure the economic efficiency, environmental efficiency, and unified efficiency of transportation infrastructure in various regions in China. The average values of the three types of efficiency from 2007 to 2017 are shown in Table 3. The results show that the average values of the economic, environmental, and unified efficiency of transportation infrastructure nationwide were, respectively, $0.902,0.657$, and 0.900 , indicating that although development of transportation infrastructure has benefited more the economy than the environment in China, the economic development and the carbon emission resulting from transportation infrastructure tend to show a benign coupling. For different regions, the average values of economic efficiency in regions not along the routes and those along the routes were, respectively, 0.904 and 0.900 ; the average values of environmental efficiency were, respectively, 0.620 and 0.685 ; and the average values of unified efficiency were, respectively, 0.904 and 0.898 . This indicates that the development of transportation infrastructure in regions not along the routes has brought good economic benefits; the development of transportation infrastructure in regions along 
TABLE 3: Average values of three types of transportation infrastructure efficiency in China, 2007-2018.

\begin{tabular}{|c|c|c|c|c|}
\hline & Region & $\mathrm{EE}$ & $\mathrm{CE}$ & UE \\
\hline \multirow{14}{*}{ Regions not along the Belt and Road } & Beijing & 0.744 & 0.554 & 0.756 \\
\hline & Tianjin & 0.979 & 0.842 & 0.981 \\
\hline & Hebei & 1.000 & 0.587 & 1.000 \\
\hline & Shanxi & 0.909 & 0.718 & 0.907 \\
\hline & Jiangsu & 0.965 & 0.401 & 0.961 \\
\hline & Anhui & 0.969 & 0.751 & 0.973 \\
\hline & Jiangxi & 0.930 & 0.809 & 0.933 \\
\hline & Shandong & 0.950 & 0.264 & 0.944 \\
\hline & Henan & 0.919 & 0.573 & 0.918 \\
\hline & Hubei & 0.787 & 0.510 & 0.771 \\
\hline & Hunan & 0.878 & 0.650 & 0.872 \\
\hline & Sichuan & 0.767 & 0.564 & 0.777 \\
\hline & Guizhou & 0.955 & 0.835 & 0.953 \\
\hline & Regional mean & 0.904 & 0.620 & 0.904 \\
\hline \multirow{18}{*}{ Regions along the Belt and Road } & Inner Mongolia & 0.872 & 0.633 & 0.863 \\
\hline & Liaoning & 0.848 & 0.431 & 0.820 \\
\hline & Jilin & 0.901 & 0.826 & 0.909 \\
\hline & Heilongjiang & 0.839 & 0.706 & 0.847 \\
\hline & Shanghai & 1.000 & 0.348 & 1.000 \\
\hline & Zhejiang & 0.865 & 0.510 & 0.850 \\
\hline & Fujian & 0.898 & 0.651 & 0.900 \\
\hline & Guangdong & 0.877 & 0.011 & 0.865 \\
\hline & Guangxi & 0.866 & 0.719 & 0.865 \\
\hline & Hainan & 0.972 & 0.957 & 0.971 \\
\hline & Chongqing & 0.856 & 0.739 & 0.864 \\
\hline & Yunnan & 0.796 & 0.691 & 0.796 \\
\hline & Shaanxi & 0.848 & 0.708 & 0.853 \\
\hline & Gansu & 0.967 & 0.903 & 0.966 \\
\hline & Qinghai & 0.998 & 0.998 & 0.998 \\
\hline & Ningxia & 1.000 & 1.000 & 1.000 \\
\hline & Xinjiang & 0.905 & 0.818 & 0.899 \\
\hline & Regional mean & 0.900 & 0.685 & 0.898 \\
\hline \multicolumn{2}{|c|}{ Mean for all regions } & 0.902 & 0.657 & 0.900 \\
\hline
\end{tabular}

Note. EE: economic efficiency; CE: environmental efficiency; UE: unified efficiency.

the routes has brought less environmental pollution; in comprehensive consideration of economic development and environmental protection, the development of transportation infrastructure in regions not along the routes has achieved better that those along the routes, but the difference is not big and the development of the regions along the routes has started catch up. In summary, the implicit assumption of economic efficiency is that there is no environmental regulation, which only focuses on economic benefits and ignores environmental pollution. Environmental efficiency refers to the performance after the implementation of energy-saving and carbon-reducing environmental regulations. It was obviously one-sided to use economic efficiency or environmental efficiency alone as a measure of the level of transportation infrastructure investment. Moreover, when economic efficiency was used as a measure, the level of investment in transportation infrastructure was often overestimated, and when environmental efficiency was used as a measure, the level of investment in transportation infrastructure was often underestimated. Therefore, we used the additive structural characteristics of the RAM model to integrate economic efficiency and environmental efficiency into a unified framework for addition, so that we could evaluate the real investment level of China's transportation infrastructure more comprehensively and accurately.

5.1.2. Temporal Trending of Efficiency. In order to understand the changes in the three types of efficiency of transportation infrastructure at the national and regional levels before and after the Belt and Road Initiative was proposed, the temporal trending of the three types was analyzed. In terms of the economic efficiency of transportation infrastructure, as shown in Figure 2, the overall economic efficiency of the country from 2007 to 2018 tended to go up, with phased changes. Among them, the economic efficiency dropped remarkably in 2009 possibly because the Chinese government spent RMB 4000 billion in the construction of transportation infrastructure to drive economic growth and alleviate the impact of the international financial crisis while economic growth of the industry was not obvious due to the lag of economic policies, resulting in redundant capital investment and reduced economic efficiency. The economic efficiency steadily increased from 2010 to 2012 possibly because the value added of transportation and the comprehensive converted turnover increased rapidly after 2010 . 


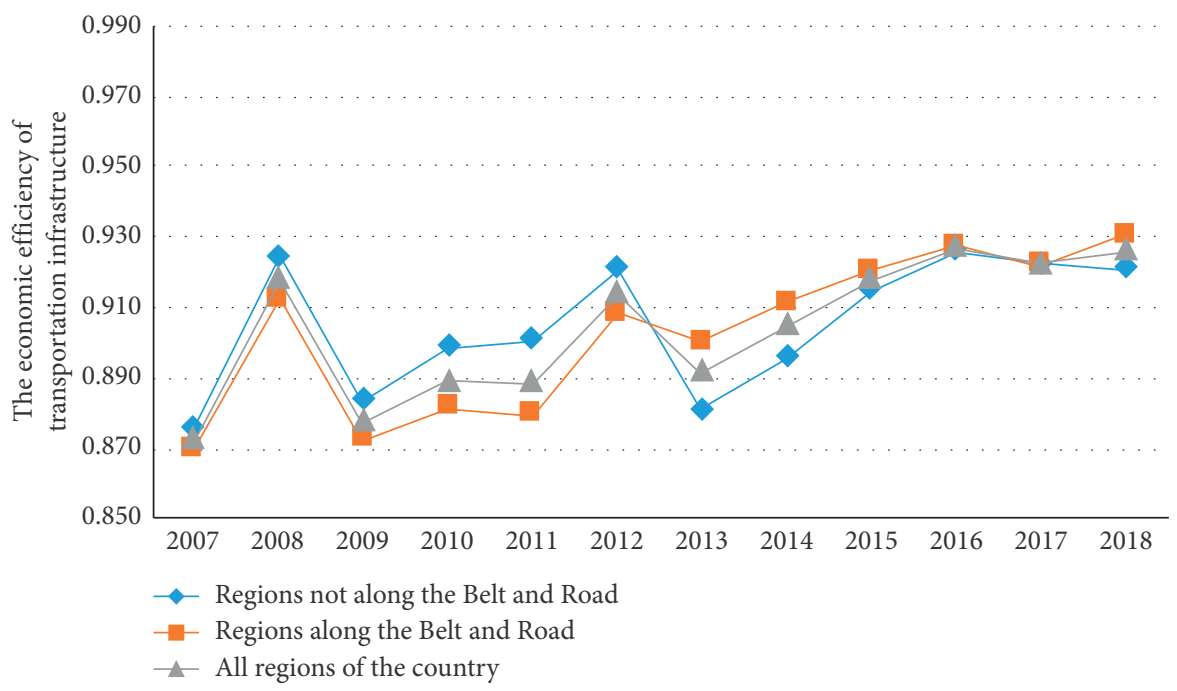

Figure 2: Trending in economic efficiency of transportation infrastructure.

The economic efficiency declined slightly in 2013 possibly because the Chinese economy entered the "new normal" stage with the implementation of a series of economic reforms and industrial upgrading, leading to a decrease in the economic efficiency of China's transportation infrastructure. After 2013, the economic efficiency grew steadily possibly because of the effects of economic reforms and proposal of the Belt and Road Initiative. In terms of regions, the general trending of economic efficiency of transportation infrastructure in regions not along the routes and that of those along the routes was similar to that of the countries at large, but the economic efficiency of regions not along the routes was higher than that of regions along the routes before 2013, mainly because these regions include the more developed provinces in central and eastern China. The economic efficiency of transportation infrastructure of the regions along the routes, covering relatively underdeveloped western provinces, was low, but it is surprising that this has changed since 2013. The economic efficiency of transportation infrastructure of the regions along the routes has started to exceed that of regions not along the routes, which is likely to be attributed to the Belt and Road Initiative.

In terms of environmental efficiency of transportation infrastructure, it can be seen from Figure 3 that the overall national environmental efficiency from 2007 to 2018 showed a steady trend, but the efficiency was not at a high level, which indicates that the industry has a great potential for energy conservation and emission reduction. This trend possibly resulted from the fact that the continuous construction and improvement of transportation infrastructure, with policy support, contributed to rapid development of the transportation industry, resulting in a leap in energy consumption and negative impacts on the environment. At the same time, in order to achieve the targets of energy conservation and emission reduction of the transportation industry, China has taken a number of measures, including construction of large-scale transportation infrastructure to alleviate air pollution caused by traffic congestion, establishment and improvement of a well-structured comprehensive transportation system with different modes complementing each other to reduce emissions, reduction of energy consumption and promotion of the use of clean energy in the transportation industry, and vigorous development of the new energy vehicle industry. Although some achievements have been made in energy conservation and emission reduction, they have been offset by the negative environmental impacts resulting from operation of largescale transportation infrastructure in recent years, and therefore the overall environmental efficiency across the country has not changed much. For different regions, the general trends of environmental efficiency of transportation infrastructure in regions not along the routes and those along the routes were similar to those of the country at large. However, the environmental efficiency of the regions along the routes has always been higher than those not long the line and the national average. It is possibly because of the low level of energy-saving technology as a whole in regions not along the routes, many of which depend more on road transportation, such as Hebei, Shandong, Henan, and Sichuan. In addition, the western regions of China, including Gansu, Qinghai, Ningxia, and Xinjiang, have higher levels of environmental efficiency of transportation infrastructure, which has contributed to the overall environmental development of the regions along the routes. Energy consumption and $\mathrm{CO}_{2}$ emission of the transportation industry in western China are both much lower than other regions despite the limited input into transportation infrastructure due to its smaller population and underdeveloped economy, and therefore the environmental efficiency calculated based on the input/output ratio is relatively high in western China.

In terms of unified efficiency of transportation infrastructure, Table 3 and Figure 4 show that, under the unified effects of economic and environmental efficiency, the overall national unified efficiency from 2007 to 2018 tended to go up with fluctuations. The average unified efficiency was 0.9, indicating that economic growth and carbon emission reduction in relation to transportation infrastructure tended to be in positive coupling in China. In general, the unified 


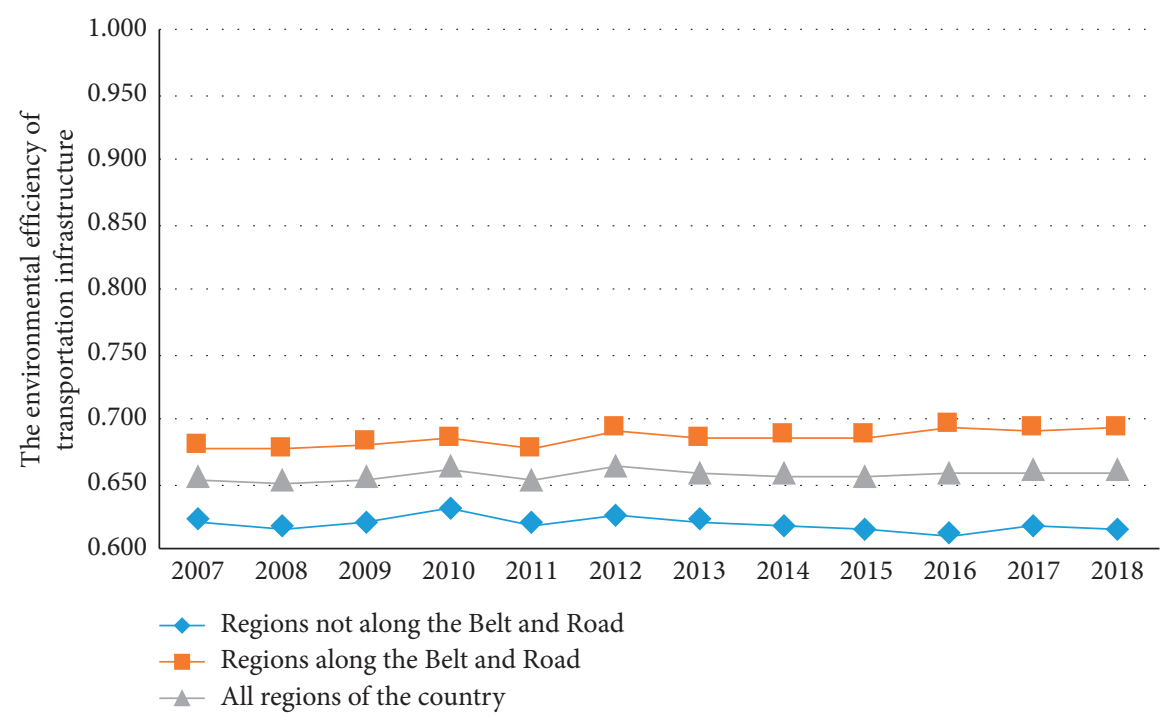

FiguRE 3: Trending in environmental efficiency of transportation infrastructure.

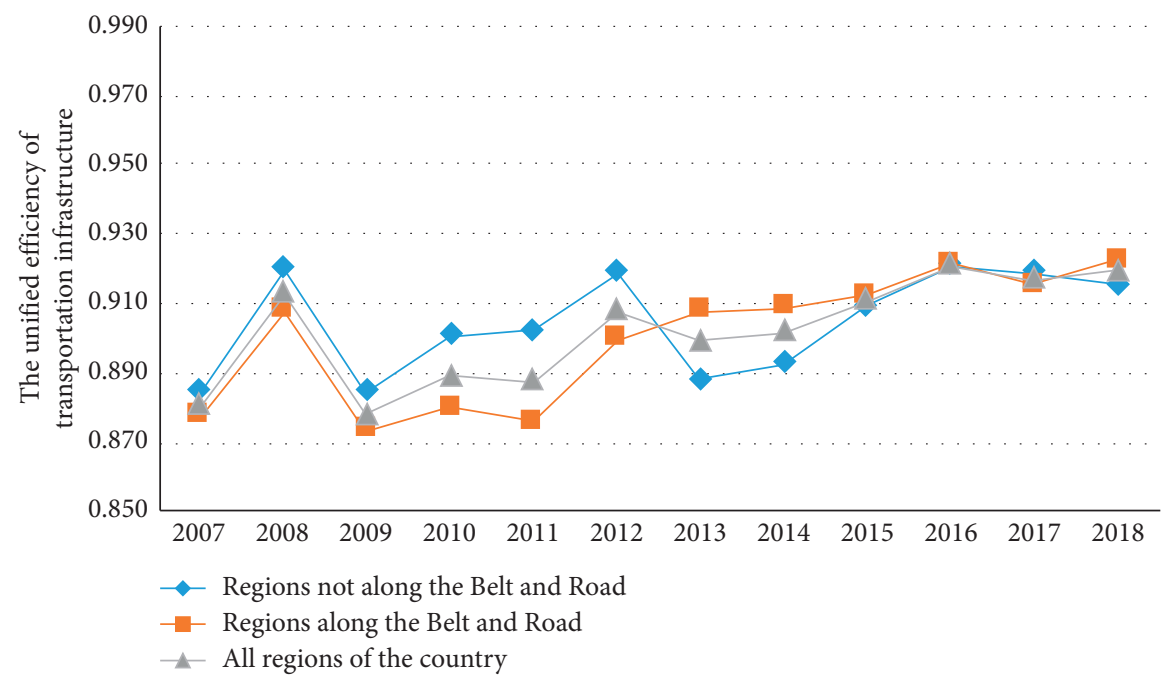

FIgURE 4: Trending in unified economic and environmental efficiency of transportation infrastructure.

efficiency from 2007 to 2018 fluctuated mostly in the same way as the economic efficiency, indicating that economic efficiency played a dominant role in this period. For different regions, the unified efficiency showed a phased tend. From 2007 to 2012, the unified efficiency in regions not along the routes was always higher than that in regions along the routes, but the latter exceeded the former from 2013 to 2015. It is possibly because the Belt and Road Initiative proposed in 2013 promoted the development of the transportation infrastructure in regions along the routes, which led to rapid economic growth resulting in an increase in the unified efficiency. In addition, the environmental efficiency of many provinces along the routes was always at a high level, which also contributed to a high unified efficiency. From 2016 to 2018, the unified efficiency of regions not along the routes was close to that of regions along the routes possibly because the economic and environmental development of the regions along the routes had a spillover effect on surrounding regions. In summary, by analyzing the trends in the economic efficiency, environmental efficiency, and unified efficiency of transportation infrastructure at the national and regional levels, it may be concluded that the Belt and Road Initiative may have contributed to the improvement of the unified efficiency of transportation infrastructure in regions along the routes, but the conclusion needs to be empirically tested later.

\subsection{Effects of the Belt and Road Initiative on the Unified Economic and Environmental Efficiency of Transportation Infrastructure}

5.2.1. DID Model Estimation Result. In this paper, Stata 15.0 was used to estimate model (9). The specific estimation results are shown in Table 4. Columns (1) and (2) are, respectively, the estimated results before and after control variables are 
TABLE 4: Effects of the Belt and Road Initiative on the unified economic and environmental efficiency of transportation infrastructure.

\begin{tabular}{lcc}
\hline Explanatory variable & $(1)$ & $(2)$ \\
\hline Silkroad * post & $0.0233(0.0187)$ & $0.0268^{*}(0.0146)$ \\
Tid & & $0.0571^{* * *}(0.0092)$ \\
Ts & & $0.0145(0.0265)$ \\
Urb & & $-0.0106(0.0485)$ \\
Open & & $-0.0028(0.0240)$ \\
Pop & & $-0.1351^{* * *}(0.0097)$ \\
Tnd & $0.9017^{* * *}(0.0061)$ & $0.0647^{* * *}(0.0111)$ \\
Constant & Yes & $2.0862^{* * *}(0.0754)$ \\
\hline Time fixed effect & Yes & Yes \\
Region fixed effect & 360 & Yes \\
Observations & 0.0165 & 360 \\
$R^{2}$ & & 0.4079 \\
\hline
\end{tabular}

Note: the standard error is shown in parentheses. ${ }^{*}, * *$, and ${ }^{* * *}$ indicate, respectively, a significance level of $10 \%, 5 \%$, and $1 \%$.

added. It can be seen that when no control variable is added, coefficient silkroad $*$ post is positive with no significance. After control variables are added, coefficient silkroad $*$ post is significantly positive at the $10 \%$ level. It can be found based on the model's $R$-squared value that the model can better interpret the assumptions after control variables are added. Therefore, it can be shown that the Belt and Road Initiative has a positive effect on the improvement of the unified economic and environmental efficiency of transportation infrastructure. Therefore, Assumption 1 is verified. Among the control variables, the development scale of the transportation industry and the density of the transportation network have a significant role in improving the unified economic and environmental efficiency of transportation infrastructure. The possible reason is that the demands for development have increased the investment level of transportation infrastructure to a certain extent, which further increases the output efficiency. The employed population has a significant negative effect. The possible reason is that the number of employed people in the existing transportation industry cannot meet the development needs of the industry, thereby reducing output efficiency; in addition, the effects of transportation structure, urbanization level, and opening-up level are not significant, indicating that they have no significant impact on the unified economic and environmental efficiency of transportation infrastructure.

5.2.2. Robustness Test. The above model estimation results show that the Belt and Road Initiative has a positive effect on the improvement of the unified economic and environmental efficiency of transportation infrastructure. In order to ensure the credibility of the results, it is necessary to conduct robustness tests to exclude other assumptions. The specific tests that are conducted are shown as follows.

(1) Parallel trend test:

To use the DID method, an important assumption should be met to ensure that the estimation result of model (9) is accurate; that is, the treated group and the control group should have the same trend before a policy event occurs. Therefore, a parallel trend test was conducted on the trends of the treated group and control group before 2013 when the Belt and Road Initiative was proposed. In the paper, the interaction coefficients of each year were compared by a DID model. The DID model established is shown as

$$
\begin{aligned}
U E_{i t}= & \beta_{0}+\beta_{k} \sum_{k \geq-3}^{3} \operatorname{silkroad}_{i} * \text { year }_{2013+k}+\alpha X_{i t}+\gamma_{t} \\
& +\mu_{i}+\varepsilon_{i t} .
\end{aligned}
$$

In the above model, year $2013+k$ is a year dummy variable, which is 1 for observation made in the current year and 0 for observation made in other years; other variables in the formula have the same meanings as those in model (9). The interaction coefficients in model within three years before and after the Initiative was proposed were compared to test whether the treated groups and the control group were in a parallel trend. The results were plotted using the coefplot command of Stata, as shown in Figure 5. The results show that the interaction coefficients before 2013 were all negative numbers fluctuating near 0 with no significance, indicating that the treated group and the control group had the same trend before the proposal of the Belt and Road Initiative. In 2013 and afterwards, the interaction coefficients increased and were significantly positive, indicating that the trend of the treated group increases more significantly than that of the control group. Therefore, the samples have passed the parallel trend test.

(2) Placebo test 1, counterfactual test:

In order to test the robustness of the estimation results, a counterfactual test was conducted, where the proposal time of the Belt and Road Initiative was changed. Specifically, it was assumed that the Belt and Road Initiative was proposed one to three years ahead of time to test whether there would still be a significant effect on the unified economic and environmental efficiency of transportation infrastructure. The results 


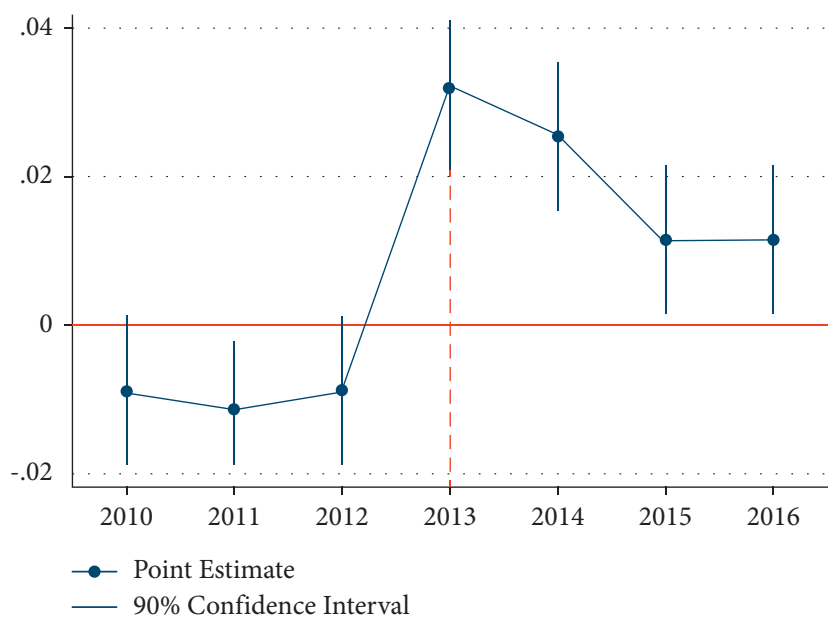

Figure 5: Interaction coefficients in different years.

are shown in Table 5. Columns (1) to (3) in the table show the estimation results when the Belt and Road Initiative was assumed to be proposed in 2010, 2011, and 2012. The coefficients of the variable silkroad $*$ post are, respectively, $0.0155,0.0183$, and 0.0216 , with no statistical significance. Therefore, effects of other policies or random factors on the unified economic and environmental efficiency of transportation infrastructure may be excluded.

(3) Placebo test 2, randomly sampled treated group:

In order to test whether the estimation results are biased due to missing variables, a placebo test on the results of the study was conducted by randomly sampling regions along the routes. 17 regions were selected randomly from the 30 regions to form a false treated group, and the remaining regions formed a false control group. The grouping dummy variable $\operatorname{silkroad}_{i}^{\text {false }}$ was thus established for the placebo test, followed by an initiative dummy variable $\operatorname{silkroad}_{i}^{\text {false }} *$ post $_{t}$. Since the false treated group is randomly formed, the initiative dummy variable for the placebo test should not have significant impact on the dependent variables in model (9), i.e., $\beta_{1}^{\text {false }}=0$. In other words, the estimated coefficient of $\beta_{1}^{\text {false }}$ would not deviate significantly from zero if there are no significant deviations due to missing variables. Otherwise, significant deviation of the estimated coefficient of $\beta_{1}^{\text {false }}$ from zero would indicate errors in the model setup. At the same time, in order to prevent interference of small probability events in the estimation, we repeated the above generation process of the treated group for 1,000 times for regression analysis. The kernel density of the estimated coefficients and distribution of the corresponding $p$ values of 1,000 randomly generated treated groups are shown in Figure 6. It can be seen from Figure 6 that the mean regression coefficient was near 0 and most $p$ values were greater than 0.1 . At the same time, the actual estimated coefficient represented by the vertical in the figure was obviously abnormal compared with the estimated coefficient in the placebo test. In summary, the estimation results did not have severe errors due to missing variables.

5.2.3. Analysis on Regional Heterogeneity. In order to further investigate whether the effects of the Belt and Road Initiative on the improvement of the unified economic and environmental efficiency of transportation infrastructure are regionally heterogeneous, this paper divided the provinces and cities into three groups: eastern, central, and western regions and conducted regression tests for each group. The specific results are shown in Table 6. The effects of the Belt and Road Initiative on the improvement of the unified economic and environmental efficiency of transportation infrastructure show obvious regional heterogeneity, which is specifically manifested as significant positive effects in the eastern region while showing negative effects in the central and western regions. The possible reason is that the economic base and economic openness vary across regions. The eastern region has a relatively developed economy and a relatively high degree of economic openness. After the Belt and Road Initiative was put forward, vigorous development of transportation infrastructure has further expanded the economic and trade level of the eastern region. Therefore, the implementation of the Belt and Road Initiative has a significant role in improving the unified economic and environmental efficiency of transportation infrastructure in the eastern region along the routes. In contrast, due to the relatively backward economy and a low degree of economic openness in the central and western regions, on the one hand, the backward transportation infrastructure has been greatly improved after the Belt and Road Initiative was put forward, but the level of development is still lagging behind. Therefore, even if new development opportunities are created for the regions, the current development level of transportation infrastructure still cannot meet the demands for regional economic and trade development, which may inhibit the regional development to some extent. On the other hand, even if the transportation infrastructure is 
TABLE 5: Effects of the Belt and Road Initiative on unified efficiency of transportation infrastructure assuming that the Initiative was proposed ahead of time.

\begin{tabular}{lccc}
\hline Explanatory variable & $(1)$ & $(2)$ & $(3)$ \\
\hline Silkroad $*$ post & $0.0155(0.0182)$ & $0.0183(0.0160)$ & $0.0216(0.0147)$ \\
Constant & $1.8598^{* * *}(0.0752)$ & $1.9488^{* * *}(0.0763)$ & Yes \\
\hline Control variable & Yes & Yes & Yes \\
Time fixed effect & Yes & Yes & Yes \\
Region fixed effect & Yes & 360 & Yes \\
Observations & 360 & 0.3621 & 360 \\
$R^{2}$ & 0.3322 & 0.4144 \\
\hline
\end{tabular}

Note: the standard error is shown in parentheses. * , **, and ${ }^{* * *}$ indicate, respectively, a significance level of $10 \%, 5 \%$, and $1 \%$.

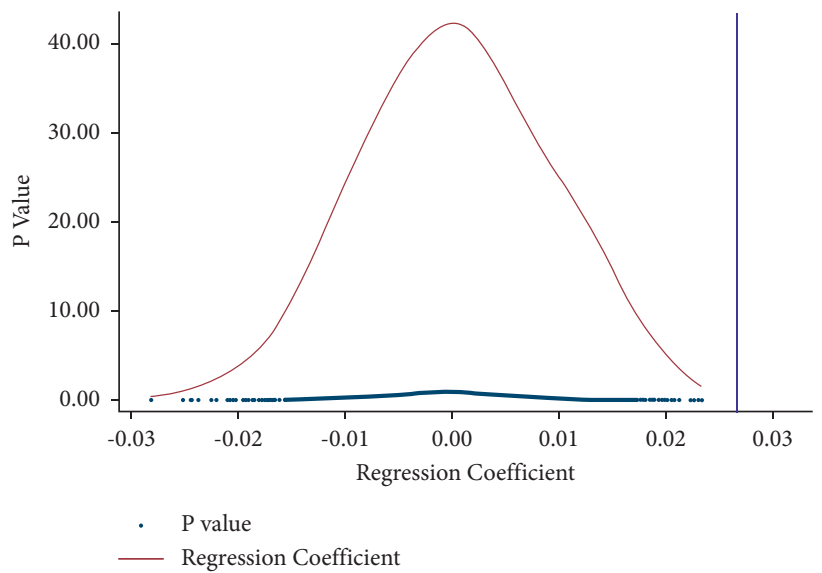

FiguRE 6: Estimated coefficients and $p$ values of a treated group randomly sampled.

TABLE 6: Regional differences in the effects of the Belt and Road Initiative on the unified economic and environmental efficiency of transportation infrastructure.

\begin{tabular}{lccc}
\hline Indicator & Eastern region & Central region & Western region \\
\hline Silkroad $*$ post & $0.0618^{* *}(0.0238)$ & $-0.0344(0.0238)$ & $-0.0146(0.0188)$ \\
Constant & $2.0008^{* * *}(0.1290)$ & $1.8901^{* * *}(0.2707)$ & $2.1573^{* * *}(0.0744)$ \\
\hline Control variable & Yes & Yes & Yes \\
Time fixed effect & Yes & Yes & Yes \\
Region fixed effect & Yes & Yes & Yes \\
Observations & 132 & 96 & 132 \\
$R^{2}$ & 0.5338 & 0.5133 & 0.7659 \\
\hline
\end{tabular}

Note: the standard error is shown in parentheses. $*, * *$, and $* * *$ indicate, respectively, a significance level of $10 \%, 5 \%$, and $1 \%$.

developed at a large scale and meets the demands for regional economic and trade development, due to the time lag of transportation infrastructure investment, it is still difficult to effectively drive the rapid development of local economy and trade in a short term. As a result, in central and western regions along the routes, the unified economic and environmental efficiency of transportation infrastructure cannot be improved by the Belt and Road Initiative for now.

\subsection{Mediation Mechanism of the Transformation and Upgrade of Industrial Structure}

5.3.1. Estimation Result of Mediation Models. The estimated results of the parallel multiple mediation models are shown in Table 7. Column (1) takes the level of industrial structure supererogation as the explained variable, and the estimated coefficient of the initiative dummy variable is significantly positive when the significance level is below $1 \%$, indicating that the Belt and Road Initiative facilitated the supererogation of the regional industrial structure. The Belt and Road Initiative, on the one hand, encourages Chinese market players to increase R\&D investment and strengthen their innovation capabilities so as to gain market opportunities; on the other hand, it advances China's technology by introducing advanced foreign technologies, equipment, and management experience, thereby helping to achieve the optimization and upgrade of industrial structure. Column (2) takes the level of industrial structure rationalization as the explained variable, and the estimated coefficient of the initiative dummy variable is significantly positive when the significance level is below $10 \%$, indicating that the Belt and 
TABLE 7: Estimation results of multiple mediation models.

\begin{tabular}{|c|c|c|c|}
\hline \multirow[b]{2}{*}{ Explanatory variable } & \multicolumn{3}{|c|}{ Explained variable } \\
\hline & $\begin{array}{l}\text { Upgrade } \\
(1)\end{array}$ & $\begin{array}{c}\text { Ration } \\
(2)\end{array}$ & $\begin{array}{l}\mathrm{UE} \\
(3)\end{array}$ \\
\hline Silkroad $*$ post & $0.2221^{* * *}(0.0223)$ & $0.0211^{*}(0.0118)$ & $0.0084^{*}(0.0043)$ \\
\hline Upgrade & & & $0.0044(0.0049)$ \\
\hline Ration & & & $0.0419^{* *}(0.0140)$ \\
\hline Constant & $3.4712^{* * *}(0.2634)$ & $0.3858^{* * *}(0.0688)$ & $1.9277^{* * *}(0.1773)$ \\
\hline Control variable & Yes & Yes & Yes \\
\hline Time fixed effect & Yes & Yes & Yes \\
\hline Region fixed effect & Yes & Yes & Yes \\
\hline Observations & 360 & 360 & 360 \\
\hline$R^{2}$ & 0.2186 & 0.6822 & 0.3877 \\
\hline
\end{tabular}

Note: the standard error is shown in parentheses. $*, * *$, and $* * *$ indicate, respectively, a significance level of $10 \%, 5 \%$, and $1 \%$.

Road Initiative has boosted the rationalized development of the regional industrial structure. The Belt and Road Initiative has established a new platform for exchange and cooperation in various fields for various regions. It not only relieves the problem of domestic overcapacity and realizes the rational allocation of production factors by stimulating domestic and foreign market demands, but also accelerates the adjustment of domestic industrial structure by taking advantage of industrial complementarity, realizing the rational layout and coordinated development of industries. Column (3) takes the unified economic and environmental efficiency of transportation infrastructure as the explained variable. The estimated coefficients of the initiative dummy variable and the industrial structure rationalization level are significantly positive when the significance level is below $10 \%$ and 5\%, respectively, while the estimated coefficient of the industrial structure supererogation level is positive but no significant, which shows that the Belt and Road Initiative and the industrial structure rationalization have enabled the improvement of the unified economic and environmental efficiency of transportation infrastructure, while the industrial structure supererogation level has no positive effects. From the perspective of industrial structure, the possible reasons could be the following: On the one hand, with our economy becomes more and more market-oriented, the industrial structure rationalization level is also high. The coordinated development of industries cannot be separated from the rational allocation of production factors, while the allocation of production factors is inseparable from the improvement of transportation infrastructure, which further drives investment into transportation infrastructure. Transportation infrastructure later effectively boosts regional economic growth through stimulating demands and lowering transaction costs and at the same time speeds up the knowledge flow and technological innovation by developing low-carbon transportation and exerting its technology spillover benefits, thereby forming a high-tech lowcarbon industry cluster and actively promoting the regional environmental development. In summary, the industrial structure rationalization has a positive role in improving the unified economic and environmental efficiency of transportation infrastructure. On the other hand, the core motivation for industrial structure supererogation lies in technological innovation, but the current lack of independent innovation capabilities weakens the core competitiveness of Chinese enterprises, which prevents, to a certain extent, the industrial value chain from shifting from low end to high end. From the perspective of resource reallocation, the large-scale development of the industry requires complete transportation infrastructure as a support. However, obviously, the current level of industrial structure supererogation has not significantly improved the unified economic and environmental efficiency of transportation infrastructure. From this point of view, the industrial structure supererogation level has not yet been able to positively facilitate the improvement of the unified efficiency of transportation infrastructure. The estimated results in columns from (1)-(3) indicate that the Belt and Road Initiative can at least improve the unified economic and environmental efficiency of transportation infrastructure by promoting the rationalization of the industrial structure. The Bootstrap method needs to be used to verify the significance of mediation paths.

5.3.2. Test on Mediation Effect Significance. This paper uses the bias-corrected percentile Bootstrap method to test the significance of the mediation effect. Specifically, in this paper, Bootstrap samples were obtained by resampling 2000 times. If a $95 \%$ confidence interval corresponding to the mediation effect does not include 0 , the mediation effect is significant. The specific test results are shown in Table 8 . It can be seen that the overall mediation effect is 0.0098 and the corresponding confidence interval does not include 0 , indicating that the overall mediation effect is significant. This result indicates that it is reasonable to use both the supererogation level and the rationalization level of industrial structure as mediating variables. The Belt and Road Initiative can improve the unified economic and environmental efficiency of transportation infrastructure by advancing and rationalizing the industrial structure. That is, the implementation of the Belt and Road Initiative can improve the unified efficiency of transportation infrastructure by transforming and upgrading the industrial structure. Therefore, Assumption 2 is verified. The mediation effects of the industrial structure supererogation level 
TABLE 8: Mediation effect results obtained by the Bootstrap method.

\begin{tabular}{lccccc}
\hline & Estimated value & Standard error & Z-statistic & $p$ value & $\begin{array}{c}\text { 95\% confidence interval } \\
\text { Lower limit }\end{array}$ \\
& & & & Upper limit \\
\hline Mediation effect of the supererogation level & 0.0011 & 0.0032 & 0.33 & 0.738 & -0.0052 \\
Mediation effect of the rationalization level & 0.0088 & 0.0040 & 2.21 & 0.027 & 0.0010 \\
Overall mediation effect & 0.0098 & 0.0042 & 2.32 & 0.020 & 0.0015 \\
\hline
\end{tabular}

TABLE 9: Estimated results of multiple mediation models for robustness test.

\begin{tabular}{|c|c|c|c|}
\hline \multirow[b]{2}{*}{ Explanatory variable } & \multicolumn{3}{|c|}{ Explained variable } \\
\hline & $\begin{array}{l}\text { Upgrade } \\
\text { (1) }\end{array}$ & $\begin{array}{c}\text { Ration } \\
(2)\end{array}$ & $\begin{array}{l}\text { UE } \\
(3)\end{array}$ \\
\hline Silkroad $*$ post & $0.2726^{* * *}(0.0218)$ & $0.0209 *(0.0117)$ & $0.0117^{* *}(0.0041)$ \\
\hline Upgrade & & & $0.0157(0.0089)$ \\
\hline Ration & & & $0.0387^{* * *}(0.0119)$ \\
\hline Constant & $3.8871^{* * *}(0.2640)$ & $0.4059^{* * *}(0.0688)$ & $2.2814^{* * *}(0.1398)$ \\
\hline Control variable & Yes & Yes & Yes \\
\hline Time fixed effect & Yes & Yes & Yes \\
\hline Region fixed effect & Yes & Yes & Yes \\
\hline Observations & 360 & 360 & 360 \\
\hline$R^{2}$ & 0.3086 & 0.6834 & 0.4722 \\
\hline
\end{tabular}

Note: the standard error is shown in parentheses. $*, * *$, and $* * *$ indicate, respectively, a significance level of $10 \%, 5 \%$, and $1 \%$.

TABLE 10: Mediation robustness test results by using the Bootstrap method.

\begin{tabular}{lccccc}
\hline & Estimated value & Standard error & $Z$-statistic & p value & $\begin{array}{c}\text { 95\% confidence interval } \\
\text { Lower limit }\end{array}$ \\
& & & & Upper limit \\
\hline Mediation effect of the supererogation level & 0.0059 & 0.0044 & 1.35 & 0.176 & -0.0026 \\
Mediation effect of the rationalization level & 0.0079 & 0.0036 & 2.21 & 0.027 & 0.0008 \\
Overall mediation effect & 0.0138 & 0.0050 & 2.77 & 0.006 & 0.0044 \\
\hline
\end{tabular}

and rationalization level are 0.0011 and 0.0088 , respectively, but the confidence interval corresponding to the effect of the former includes 0 while that of the latter does not. This indicates that the individual mediation effect of the industrial structure supererogation level is not significant but that of the industrial structure rationalization level is the opposite. The result shows that the Belt and Road Initiative improves the unified economic and environmental efficiency of transportation infrastructure by mainly promoting the rationalization of the industrial structure.

5.3.3. Robustness Test. In order to ensure the reliability of the empirical results, this paper conducted a robustness test and retested the mediation effect by replacing the measurement indicators of mediating variables. The industrial structure supererogation level was measured with reference to existing methods using the hierarchy coefficient [64]. The formula used in the calculation is Upgrade $_{i t}=\sum_{m=1}^{3} y_{\text {mit }} \times i$, where $y_{\text {mit }}$ is the ratio of the output value of industry $m$ in the $t$ th year of region $i$ to the local GDP in the same year. A larger hierarchy coefficient indicates a higher level of industrial structure supererogation. The level of industrial structure rationalization was measured with reference to existing methods using the industrial structure deviation [65]. The formula used in the calculation is Ration $_{i t}=\sum_{m=1}^{3}\left|Y_{\text {mit }} / L_{\text {mit }} / Y_{i t} / L_{i t}-1\right|=$ $\sum_{m=1}^{3}\left|Y_{\text {mit }} / L_{\text {mit }} / Y_{i t} / L_{i t}-1\right|$, where $Y_{\text {mit }}$ and $L_{\text {mit }}$ are, respectively, the output value and number of employees of industry $m$ in the $t$ th year of region $i$. A greater deviation indicates a less rational industrial structure. Similarly, the range transformation method was used to forward the industrial structure rationalization level. The specific test results are shown in Tables 9 and 10. It can be seen that, compared with Table 7, only estimated coefficients of main variables were changed slightly and there were no significant changes in the sign and significance of estimated coefficients in Table 9. Bootstrapping samples were also obtained by sampling for the same number of times. The significance of the individual mediation effect and overall mediation effect on Table 10 was consistent with those in Table 8 . Therefore, the study conclusions of this paper are relatively robust.

\section{Conclusions}

In order to carry out a series of the Belt and Road cooperation between countries along the routes, interconnectivity of transportation infrastructure needs to be regarded as the prerequisite and basis. The improvement of transportation infrastructure can encourage countries along the routes to participate in the Belt and Road cooperation and drive their development in various fields. To examine the comprehensive 
effects that the Belt and Road Initiative has on the economy and environment by promoting the transportation infrastructure construction, this paper takes China as the study subject, evaluates the effects of the Belt and Road Initiative on the unified economic and environmental efficiency of transportation infrastructure, and analyzes the mediating role played by the transformation and upgrade of the industrial structure. The results show that, first, the Belt and Road Initiative has different effects on the unified economic and environmental efficiency of transportation infrastructure. Nationally, the Belt and Road Initiative has a positive role in improving the unified economic and environmental efficiency of transportation infrastructure. Regionally, the Belt and Road Initiative has positive effects on improving the unified economic and environmental efficiency of transportation infrastructure in the developed eastern region, while having no effect on the underdeveloped central and western regions. Second, the Belt and Road Initiative can significantly improve the unified economic and environmental efficiency of transportation infrastructure through industrial structure transformation and upgrade, but only one of the dimensions of industrial structure transformation and upgrading, which is the level of industrial structure rationalization, has played a significant mediating role.

The policy implications brought by the above conclusions to further take advantage of Belt and Road development opportunities and improve the unified economic and environmental efficiency of transportation infrastructure include the following:

First, in order to achieve sustainable development, the country should take advantage of cooperation opportunities brought by the Belt and Road Initiative and continue conducting large-scale transportation infrastructure construction. Based on the above conclusions, it can be seen that the Belt and Road Initiative can indeed bring about a positive coupling between economic development and carbon emission through construction of large-scale transportation infrastructure. Therefore, the vigorous development of transportation infrastructure in the countries along the routes contributes to sustainable development of those countries.

Second, the government should increase the construction of transportation infrastructure in underdeveloped central and western regions to meet the surge in economic and trade demands generated under the Belt and Road Initiative. This can ultimately increase the positive effects of the Belt and Road Initiative on the unified economic and environmental efficiency of transportation infrastructure in those regions.

Third, the government should strive to improve the level of industrial structure transformation and upgrade and achieve a balanced development in the dimensions of industrial structure supererogation and rationalization, so as to increase the positive effects of the Belt and Road Initiative on the unified economic and environmental efficiency of transportation infrastructure. As the core driving force for advancing the industrial structure supererogation is technological innovation, the government should support the development of high value-added industries and guide foreign investment in this industry. The current dilemma faced by the rationalized development of industrial structure lies in the problem of overcapacity. Therefore, the government's top priority is to achieve the rational allocation of production factors by stimulating domestic and foreign market demands. In addition, the government can open up foreign trade channels by constructing international free trade zones in order to facilitate the advanced and rationalized development of industrial structure.

Compared with previous studies, the main contributions of this paper are as follows: First, based on the concept of sustainable development, this paper measured the investment level of transport infrastructure through the inputoutput ratio between transport infrastructure investment and comprehensive economic and environmental development, i.e., through the unified economic and environmental efficiency of transportation infrastructure. Second, many studies have stated that the Belt and Road Initiative has an important impact on transportation infrastructure at the theoretical level. This paper empirically investigated the impact of the Belt and Road Initiative on the unified economic and environmental efficiency of transportation infrastructure in China by building a model. To sum up, this paper provided a more comprehensive and reasonable evaluation method for the investment level of transportation infrastructure from the perspective of sustainable development. In addition, this paper provided the empirical evidences to evaluate the implementation effects of the Initiative in the transportation infrastructure sector and verifies that countries along the routes can achieve sustainable development through large-scale transportation infrastructure construction under the Belt and Road Initiative. In addition to theoretical contributions, this paper has some shortcomings. First, this paper only took China as the study subject and did not expand the scope of research to all other countries along the routes. Therefore, this may lead to limitations in the research conclusions and the study subjects need to be expanded in the future. Second, this paper mainly studied the mediating role played by the transformation and upgrade in the improvement of the unified economic and environmental efficiency of transportation infrastructure enabled by the Belt and Road Initiative. It is necessary to explore other mediating variables in future studies.

\section{Data Availability}

All data, models, and code generated or used during the study appear in the submitted article.

\section{Conflicts of Interest}

The author declares that there are no conflicts of interest. 


\section{Acknowledgments}

This paper was supported by the Scientific Research Support Program of Xi'an University of Finance and Economics (21FCJH010), the Key Project of Xi'an Social Science Planning Fund in 2020 (JG107), the Key Scientific Research Project of Shaanxi Provincial Department of Education in 2020 (20JZ051), and Department of Education of Guangdong Province's Key Scientific Research Platform and Scientific Research Projects (2018GWQNCX049). Thanks are due to Prof. Guoguang Zhou, Dr. Xiao Wei, and Dr. Ting Li for their help and support.

\section{References}

[1] Asian Infrastructure Investment Bank, https://www.aiib.org/ en/index.html, 2021.

[2] Belt and Road Portal, " 34 projects have been signed and the committed investment amount is about 12.3 billion US dollars," 2021, https://www.yidaiyilu.gov.cn/index.html.

[3] P. N. Rosenstein-Rodan, "Problems of industrialisation of eastern and south-eastern europe," The Economic Journal, vol. 53, no. 210/211, pp. 202-211, 1943.

[4] W. W. Rostow, The Stages of Economic Growth: A Noncommunist Manifesto, Cambridge University Press, Cambridge, UK, 1961.

[5] D. A. Aschauer, "Is public expenditure productive?" Journal of Monetary Economics, vol. 23, no. 2, pp. 177-200, 1989.

[6] S. Bougheas, P. O. Demetriades, and T. P. Mamuneas, "Infrastructure, specialization, and economic growth," Canadian Journal of Economics/Revue Canadienne d'Economique, vol. 33, no. 2, pp. 506-522, 2000.

[7] Z. Sun, G. Yang, and K. Li, "Is there A turning point in the contribution of infrastructure investment on economic growth: evidence from China's economic development," Finance and Economics, no. 6, pp. 75-84, 2014.

[8] C. Shirley and C. Winston, "Firm inventory behavior and the returns from highway infrastructure investments," Journal of Urban Economics, vol. 55, no. 2, pp. 398-415, 2004.

[9] Y. Y. Zhang, J. P. Yu, and D. X. Li, “Transport infrastructure and economic growth: based on "the belt and road" nation's railway transportation infrastructure," World Economy Studies, no. 3, pp. 56-68, 2018.

[10] N. Limao and A. Venables, "Infrastructure, geographical disadvantage, transport costs, and trade," The World Bank Economic Review, vol. 15, no. 3, pp. 451-479, 2001.

[11] B. Shepherd and J. S. Wilson, "Trade, infrastructure, and roadways in europe and central asia: new empirical evidence," Journal of Economic Integration, vol. 22, no. 4, pp. 723-747, 2007.

[12] M. Gonzalez-Navarro and C. Quintana-Domeque, "Paving streets for the poor: experimental analysis of infrastructure effects," The Review of Economics and Statistics, vol. 98, no. 2, pp. 254-267, 2016.

[13] A. Atkeson and A. Burstein, "Pricing-to-Market, trade costs, and international relative prices," The American Economic Review, vol. 98, no. 5, pp. 1998-2031, 2008.

[14] X. L. Zhang and H. M. Sun, "Transport infrastructure, spatial cluster and China's economic growth," Economic Survey, no. 2, pp. 20-23, 2008.

[15] S. P. Huang and Y. Zhu, "Spatial spillover effects of railway and highway transportation infrastructure on economic growth: a case of the Yangtze river delta," East China Economic Management, vol. 31, no. 11, pp. 20-27, 2017.

[16] C. R. Hulten, E. Bennathan, and S. Srinivasan, "Infrastructure, externalities, and economic development: a study of the Indian manufacturing industry," The World Bank Economic Review, vol. 20, no. 2, pp. 291-308, 2006.

[17] A. Wróbel, E. Rokita, and W. Maenhaut, "Transport of trafficrelated aerosols in urban areas," The Science of the Total Environment, vol. 257, no. 2, pp. 199-211, 2000.

[18] Z. Luo, G. Wan, C. Wang, and X. Zhang, "Urban pollution and road infrastructure: a case study of China," China Economic Review, vol. 49, no. 1, pp. 171-183, 2018.

[19] R. Tan, K. Liu, and B. Lin, "Transportation infrastructure development and China's energy intensive industries - a road development perspective," Energy, vol. 149, pp. 587-596, 2018.

[20] R. B. Liang and P. H. Xi, "Heterogeneous effects of rail transit on air pollution: an empirical study with RDID," China Industrial Economics, no. 3, pp. 83-98, 2016.

[21] G. Dalkic, O. Balaban, H. Tuydes-Yaman, and T. CelikkolKocak, "An assessment of the $\mathrm{CO}_{2}$ emissions reduction in high speed rail lines: two case studies from Turkey $\mathrm{CO}_{2}$ emissions reduction in high speed rail lines: two case studies from Turkey," Journal of Cleaner Production, vol. 165, pp. 746-761, 2017.

[22] Y. Sun, Y. Cui, and Y. C. Feng, "Evaluating the coordinated development of economic, social and environmental benefits for urban public transportation infrastructure," Review of Economy and Management, no. 6, pp. 122-135, 2019.

[23] A. H. Munnell, "Why has productive growth declined? Productivity and public investment," New England Economic Review, vol. 30, pp. 3-22, 1990.

[24] Y. Liu, "Transport infrastructure investment, regional economic growth and the spatial spillover effects: based on highway and marine's panel data analysis," China Industrial Economics, vol. 12, pp. 37-46, 2010.

[25] P. Cantos, M. Gumbau-Albert, and J. Maudos, "Transport infrastructures, spillover effects and regional growth: evidence of the Spanish case," Transport Reviews, vol. 25, no. 1, pp. 25-50, 2005.

[26] A. Charnes, W. W. Cooper, and E. Rhodes, "Measuring the efficiency of decision making units," European Journal of Operational Research, vol. 2, no. 6, pp. 429-444, 1979.

[27] R. D. Banker, "Estimating most productive scale size using data envelopment analysis," European Journal of Operational Research, vol. 17, no. 1, pp. 35-44, 1984.

[28] Z. F. Li and Y. L. Li, "An empirical study on performance evaluation of infrastructure investment of China based on DEA method from 2003 to 2007," Journal of Systems Management, vol. 18, no. 3, pp. 309-315, 2009.

[29] Y. Sun, K. Y. Wang, and X. D. Yao, "Economic benefits evaluation of urban public infrastructure based on the DEA cross-efficiency method," China Soft Science, vol. 1, pp. 172182, 2015.

[30] Q. Su, "Long-term flood risk assessment of watersheds under climate change based on the game cross-efficiency DEA," Natural Hazards, vol. 104, no. 3, pp. 2213-2237, 2020.

[31] Q. Su and X. Chen, "Efficiency analysis of metacoupling of water transfer based on the parallel data envelopment analysis model: a case of the South-North Water Transfer ProjectMiddle route in China," Journal of Cleaner Production, vol. 313, no. 6, Article ID 127952, 2021. 
[32] J. W. Forrester, "Industrial dynamics: a major breakthrough for decision makers," The Roots of Logistics, vol. 36, no. 4, pp. 141-172, 2012.

[33] W. S. Mcculloch and W. Pitts, "A logical calculus of the ideas immanent in nervous activity," Bulletin of Mathematical Biophysics, vol. 5, no. 4, pp. 115-133, 1943.

[34] S. L. Liu and A. G. Hu, "Transportation infrastructure and regional economic integration in China," Economic Research Journal, no. 3, pp. 72-82, 2011.

[35] J. Gong and Z. M. Yin, "The effect of railroads on trade along the belt and road initiative: a heterogeneity stochastic frontier model analysis based on transportation time and distance," Journal of International Trade, no. 2, pp. 14-25, 2016.

[36] J. J. Li and J. C. Li, "The belt one road infrastructure construction, economic development and financial factors," Studies of International Finance, no. 2, pp. 8-18, 2018.

[37] J. Xu, K. M. Chen, S. F. Yang, and Y. J. Lin, "The impact of economic corridor transportation infrastructure under "the belt and road initiative" based on GTAP model," Asia-pacific Economic Review, vol. 3, pp. 3-11, 2016.

[38] Fitch solutions website, https://www.fitchsolutions.com, 2020.

[39] China International Contractors Association, The Belt and Road Infrastructure Development Index Report 2019, China International Contractors Association, Beijing, China, 2019.

[40] S. C. Zhang, "Ideas and countermeasures for optimizing the layout of China's foreign direct investment under the "The Belt and Road" strategy," Management World, no. 4, pp. 1-9, 2017.

[41] Y. J. Cheng, "Foreign trade and environmental pollution: an empirical analysis based on the perspective of transportation infrastructure," Modernization of Management, no. 4, pp. 108-110, 2019.

[42] F. Butollo and T. Ten Brink, "A great leap? Domestic market growth and local state support in the upgrading of China's LED lighting industry," Global Networks, vol. 18, no. 2, pp. 285-306, 2017.

[43] M. Ishida, T. Machikita, and Y. Ueki, "How export and import platforms drive industry upgrading: five facts about emerging multinationals from southeast Asia," Asian Journal of Technology Innovation, vol. 21, pp. 4-24, 2013.

[44] D. Ernst, "Upgrading through innovation in a small network economy: insights from Taiwan's IT industry," Economics of Innovation and New Technology, vol. 19, no. 4, pp. 295-324, 2010.

[45] Y. Lu and L. Yu, "Trade liberalization and markup dispersion: evidence from China's WTO accession," American Economic Journal: Applied Economics, vol. 7, no. 4, pp. 221-253, 2015.

[46] C. W. Yuan, S. Zhang, P. Jiao, and D. Y. Wu, “Temporal and spatial variation and influencing factors research on total factor efficiency for transportation carbon emissions in China," Resources Science, vol. 39, no. 4, pp. 687-697, 2017.

[47] S. Zhang, Research on Carbon Emission and Economic Efficiency of Transportation Based on RAM Model, Chang'an university, Xi'an, China, 2018.

[48] IPCC 2006, IPCC Guidelines for National Greenhouse Gas Inventories, IGES, Japan, 2006.

[49] Y. Lyu, Y. Lu, S. B. Wu, and Y. Wang, "The effect of the belt and road initiative on firms'OFDI: evidence from China's greenfield investment," Economic Research Journal, vol. 9, pp. 187-202, 2019.

[50] National development and reform commission of the people's Republic of China, "Ministry of foreign affairs of the people's Republic of China," in Vision And Actions On Jointly Building
Silk Road Economic Belt and 21st-CenturyMaritime Silk Road, Beijing, China, 2015.

[51] J. J. Li and J. C. Li, "Has B\&R initiative improved infrastructure performance in B\&R countries?" Journal of Lanzhou University, no. 4, pp. 61-73, 2018.

[52] G. G. Zhou, Y. J. Wang, J. W. Gui, and P. X. Bai, "Research on the effect of transportation infrastructure investment in provinces and cities Along "the belt and road": a comparative analysis based on private investment and public investment," East China Economic Management, vol. 33, no. 12, pp. 5-12, 2019.

[53] C. H. Gan, R. G. Zheng, and D. F. Yu, "An empirical study on the effects of industrial structure on economic growth and fluctuations in China," Economic Research Journal, vol. 5, pp. 4-16, 2011.

[54] D. P. MacKinnon, C. M. Lockwood, J. M. Hoffman, S. G. West, and V. Sheets, "A comparison of methods to test mediation and other intervening variable effects," Psychological Methods, vol. 8, no. 1, pp. 1-35, 2002.

[55] K. J. Preacher and A. F. Hayes, The Sage Sourcebook of Advanced Data Analysis Methods for Communication Research, Sage Publications, Thousand Oaks, CA, USA, 2008.

[56] A. J. Fairchild and S. D. Mcquillin, "Evaluating mediation and moderation effects in school psychology: a presentation of methods and review of current practice," Journal of School Psychology, vol. 48, no. 1, pp. 53-84, 2010.

[57] M. S. Fritz and D. P. MacKinnon, "Required sample size to detect the mediated effect," Psychological Science, vol. 18, no. 3, pp. 233-239, 2007.

[58] A. F. Hayes and B. K. S. Beyond, "Beyond baron and kenny: statistical mediation analysis in the new millennium," Communication Monographs, vol. 76, no. 4, pp. 408-420, 2009.

[59] D. P. MacKinnon, Introduction to Statistical Mediation Analysis, Erlbaum, Mahwah, NJ, USA, 2008.

[60] D. P. MacKinnon, C. M. Lockwood, and J. Williams, "Confidence limits for the indirect effect: distribution of the product and resampling methods," Multivariate Behavioral Research, vol. 39, no. 1, pp. 99-128, 2004.

[61] I. Ntzoufras, Bayesian Modeling Using WinBUGS, Wiley, Hoboken, NJ, USA, 2009.

[62] Y. Yuan and D. P. MacKinnon, "Bayesian mediation analysis," Psychological Methods, vol. 14, no. 4, pp. 301-322, 2009.

[63] Z. Wen and B. Ye, "Analyses of mediating effects: the development of methods and models," Advances in Psychological Science, vol. 22, no. 5, pp. 731-745, 2014.

[64] J. Ke, "The relationship between industrial structure upgrading and economic growth," Statistics \& Decisions, no. 11, pp. 83-84, 2008.

[65] K. S. Zhang and D. F. Gao, "Empirical research on coordination between industrial structure and employment structure in liaoning, China," Chinese Journal of Population Science, no. 6, pp. 80-128, 2013. 